\title{
A 10 Year Autopsy Study of Hospital Deaths Brought to the Mortuary of a Tertiary Care Hospital in North East India
}

\author{
Memchoubi Phanjoubam¹, Th. Meera Devi ${ }^{2}$, Seram Elizabeth Devi ${ }^{3}$, Lynda B. Zohlupuii ${ }^{3}$ \\ ${ }^{1}$ Associate Professor, ${ }^{2}$ Professor and Head, ${ }^{3}$ Post Graduate Trainee, \\ Department of Forensic Medicine and Toxicology, Regional Institute of Medical Sciences, Imphal
}

\begin{abstract}
Without autopsies, hospitals bury their mistakes. However, not every hospital death is autopsied. As a result, experts say, diagnostic errors are missed, opportunities to improve medical treatment are lost and health-care statistics are skewed. In this 10 year retrospective study, hospital death cases which were brought for autopsy were analyzed with respect to year wise incidence, sex and age wise incidence, reasons for hospitalization and cause of death to ascertain whether the deaths were due to medical negligence or due to natural course of events of the disease. The findings reveal that $40 \%$ of the cases were due to negligence. This substantial loss could have been prevented if timely intervention was done. The study aims to highlight this important aspect of medical practice.
\end{abstract}

Keywords: Hospital deaths, autopsies, medical negligence.

\section{Introduction}

Without autopsies, hospitals bury their mistakes. Hospital autopsies have become a rarity. As a result, experts say, diagnostic errors are missed, opportunities to improve medical treatment are lost and health-care statistics are skewed. Studies have placed the number of deaths as high as 250,000 deaths per year, which would make medical error the third leading cause of death, behind cancer and cardiovascular disease. ${ }^{1}$ It is also shown that the number of previously healthy people who die every year from hospital error is about 7,150. The remainder of preventable deaths occurred in patients with less than a three-month life expectancy. Most of the hospital errors involved poor monitoring or management of medical conditions, diagnostic errors and errors related to surgery and procedures, the study shows. ${ }^{2}$

\section{Corresponding Author:}

\section{Memchoubi Phanjoubam}

Associate Professor, Department of Forensic Medicine and Toxicology, Regional Institute of Medical Sciences, Imphal

e-mail: mem010177@gmail.com
Material and Method: After obtaining ethical clearance from the institute's Research Ethics Board, a retrospective analysis of post mortem records of hospital death cases brought for autopsy to the morgue of a tertiary care hospital in North East India was done. The period was from 2010 to 2019. Cases were analyzed with respect to year wise incidence, sex and age wise incidence, reasons for hospitalization and cause of death to ascertain whether the deaths were due to medical negligence or due to natural course of the disease. Findings are the compared with prevailing trends elsewhere in the world.

Results and Observations: Fig. 1 shows the year wise incidence. Cases were maximum in 2016 and show a gradual increasing trend towards the later part of the study period as shown in Fig. 1.

Male and female cases were equal in number i.e., $50 \%$ each (Fig. 2).

As shown in Fig. 3, regarding the age wise incidence, cases were maximum in the $31-40 \mathrm{yr}(31.8 \%)$ followed by $51-60 \mathrm{yr}(22.7 \%)$ and least in the lower age groups.

Fig. 4 shows the reasons for hospitalization. Heart disease was the main reason for hospitalization followed by delivery. 
Fig. 5 shows that $40.9 \%$ of the deaths were due to medical negligence or gross medical error.

The various causes of death are shown in Table 1. Myocardial infarction was the commonest cause of death followed by followed by bronchopneumonia and coronary artery disease. Out of the 6 cases which were brought for delivery, 5 parturients and I newborn died during or after delivery. Cervical haematoma and post partum haemorrhage (PPH) following Normal Vaginal Delivery (NVD), Post Caesarian Section(CS) amniotic fluid embolism, Intrapartum haemorrhage and
Post-partum haemorrhage following Normal Vaginal Delivery, Uterine rupture during Caesarian Section, Post-partum haemorrhage following Caesarian Section and Suffocation of newborn with mucoid substance due to non-suction following Normal Vaginal Delivery were the various causes of mortality.

In one case, Lung injury following intercostal tube insertion was the cause of death.

The remaining included deaths due to cirrhosis ( 2 cases) and cysticercosis (1 case).

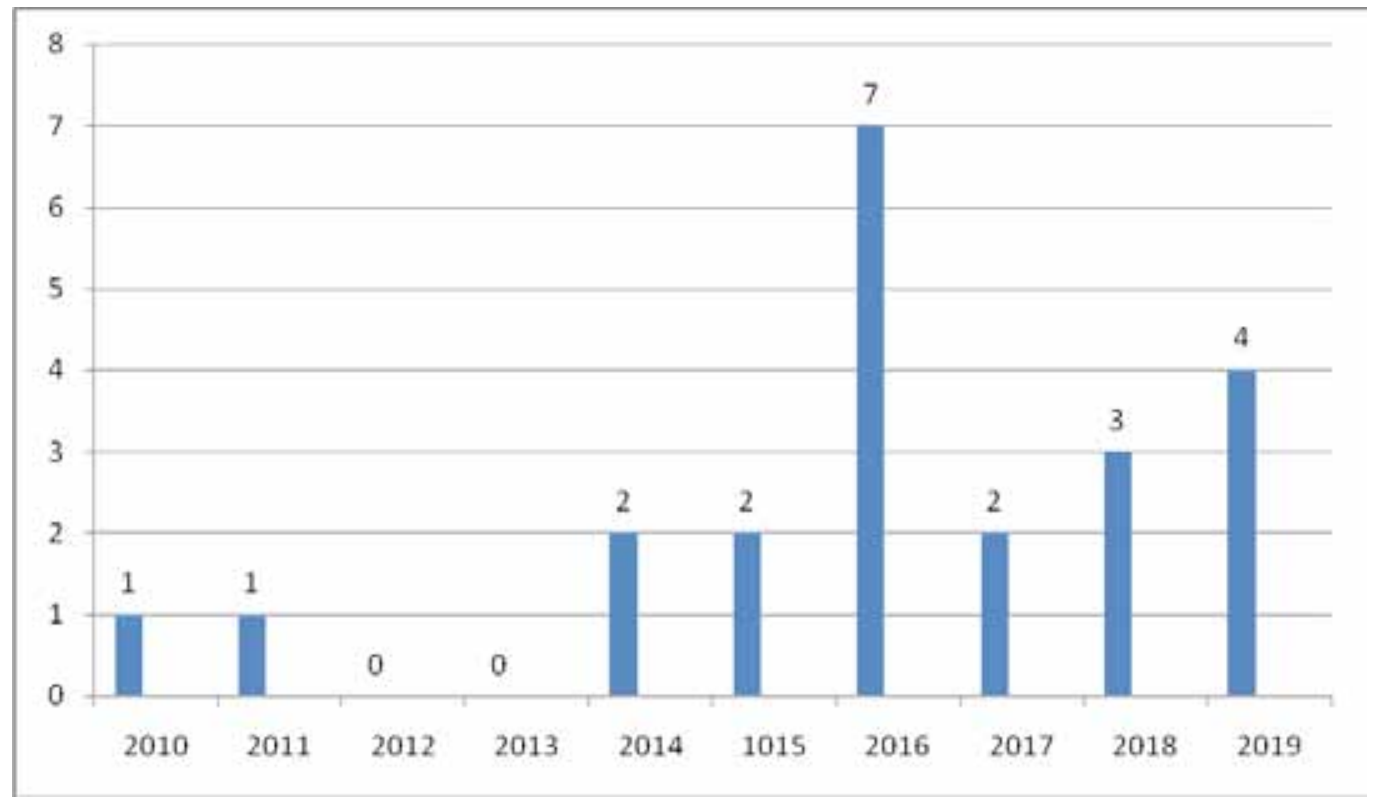

Fig. 1: Year wise distribution

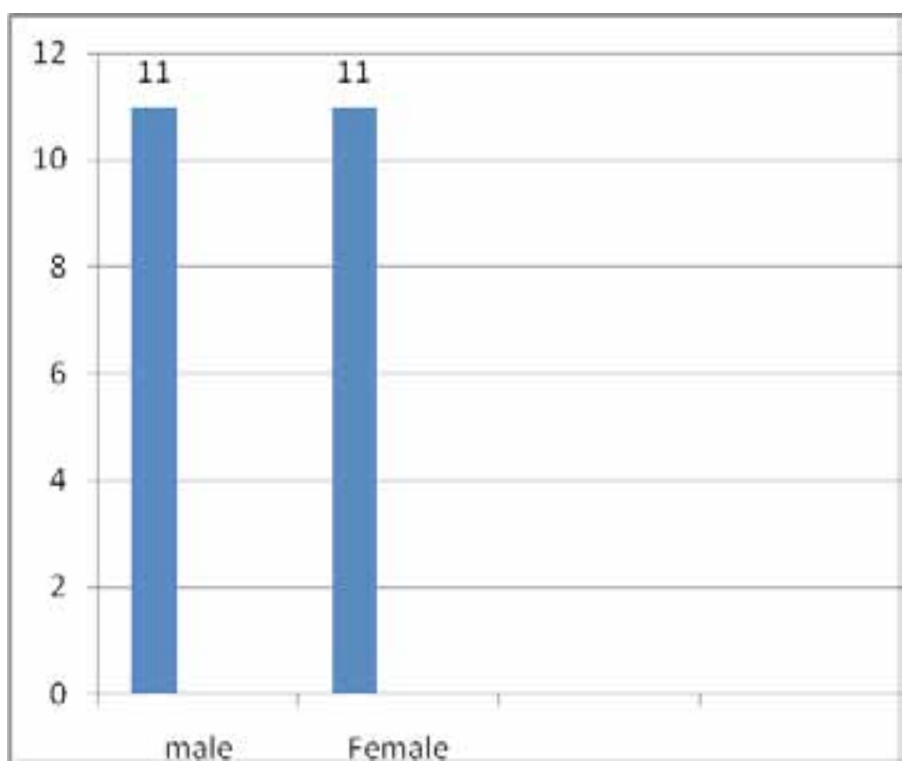

Fig. 2: Sex wise distribution 


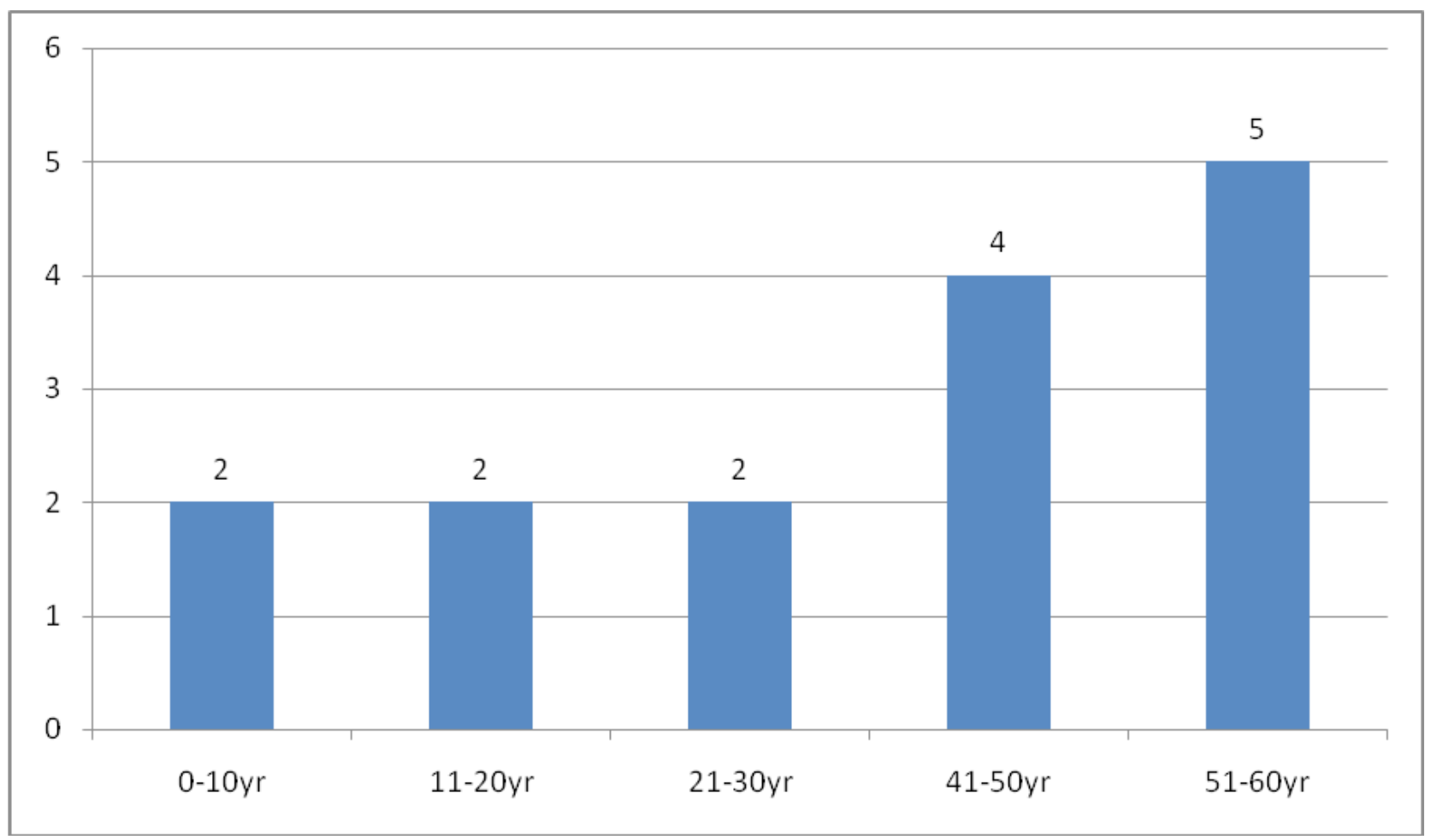

Fig 3: Age wise distribution

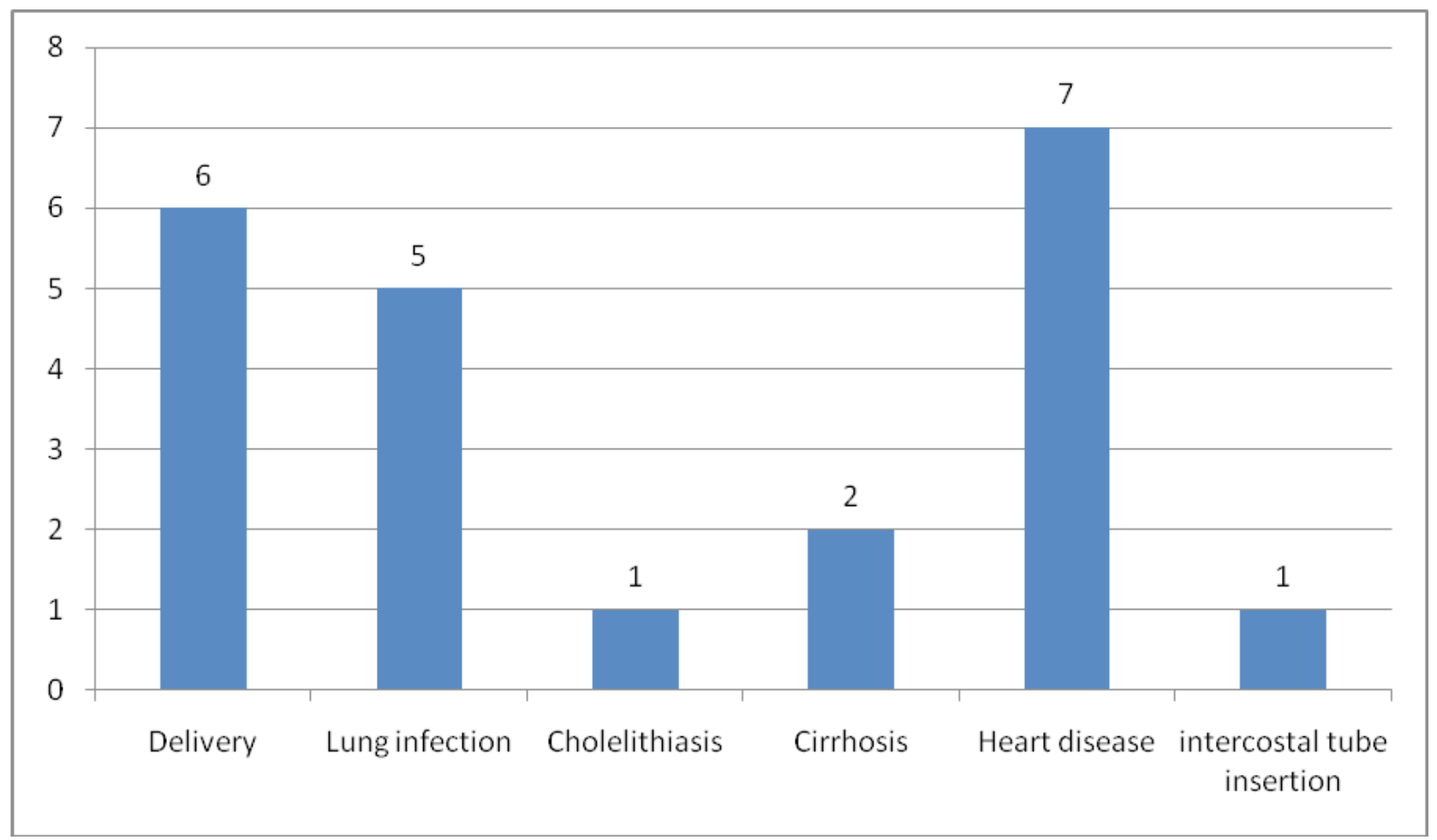

Fig 4: Reasons for hospitalisation 


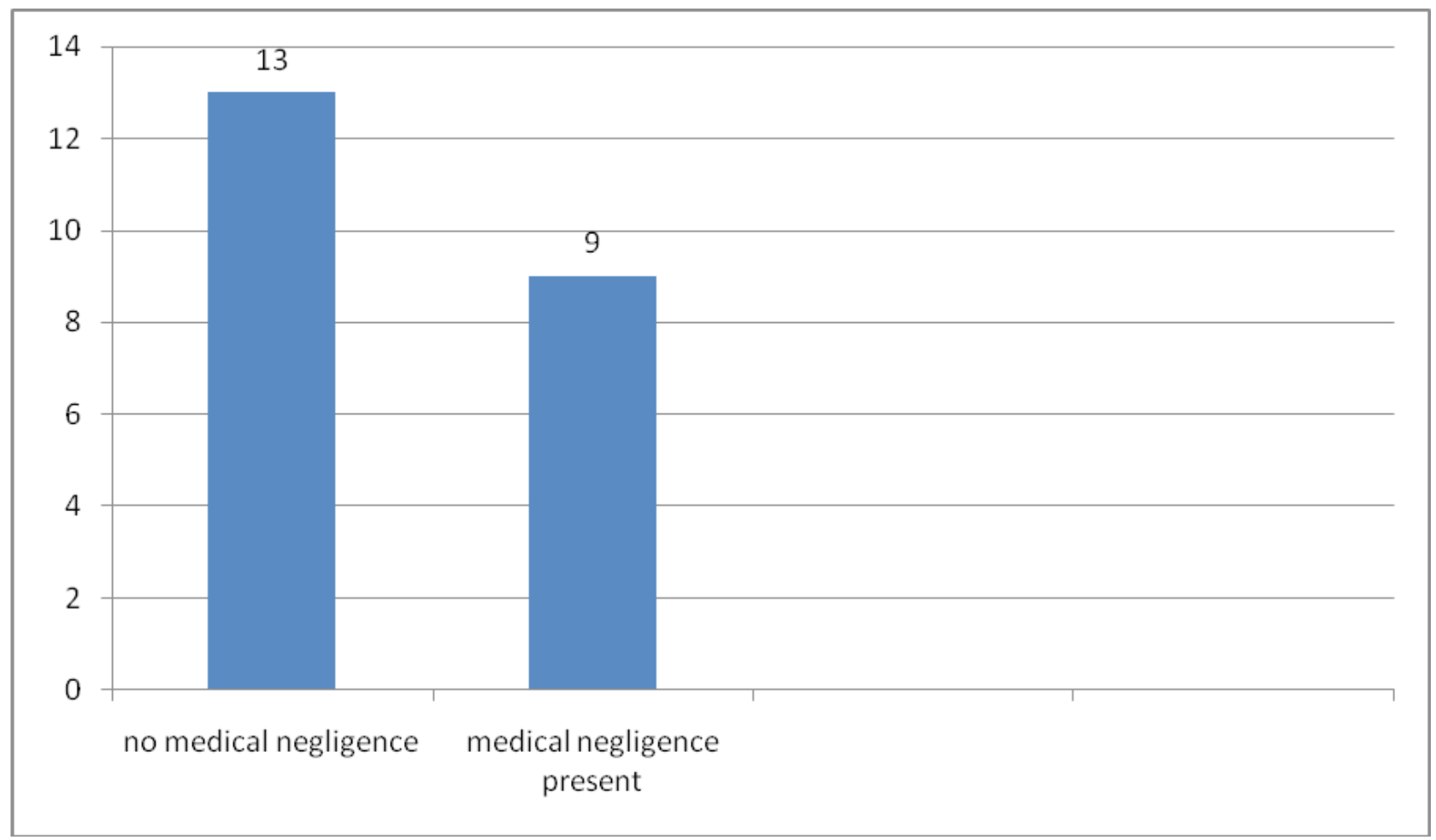

Fig. 5: Manner of death

Table 1: Causes of death

\begin{tabular}{|l|c|}
\hline Illness & No. of cases \\
\hline $\begin{array}{l}\text { Cervical haematoma and PPH following } \\
\text { NVD }\end{array}$ & 1 \\
\hline Bronchopneumonia & 1 \\
\hline $\begin{array}{l}\text { Post operative haemorrhage (GB \& } \\
\text { appendix) }\end{array}$ & 1 \\
\hline Cirrhosis & 1 \\
\hline Post CS amniotic fluid embolism & 2 \\
\hline Chronic hepatitis \& cirrhosis & 1 \\
\hline $\begin{array}{l}\text { Intrapartum and post partum haemorrhage } \\
\text { foll. NVD }\end{array}$ & 1 \\
\hline $\begin{array}{l}\text { Pulmonary oedema due to } \\
\text { neurocysticercosis }\end{array}$ & 2 \\
\hline Coronary artery disease & 5 \\
\hline Myocardial infarction & 1 \\
\hline Uterine rupture during LSCS & 1 \\
\hline $\begin{array}{l}\text { Suffocation of newborn with mucoid } \\
\text { substance due to non-suction foll. NVD }\end{array}$ & 22 \\
\hline PPH foll. CS & 1 \\
\hline Lung injury foll. intercostal tube insertion & 1 \\
\hline Total & 1 \\
\hline
\end{tabular}

\section{Discussion}

In a review of the patient records of 100 adults who died in 10 hospitals across England in 2009, it was observed that one death in 20 had a greater than 505 chance of being preventable. ${ }^{3}$ In the present study, it is evident from the findings that $40.9 \%$ of the cases could be due to medical negligence or gross medical error.

In the present study, delivery related deaths were maximum among the deaths due to medical negligence. Post partum haemorrhage, uterine rupture and amniotic fluid embolism were the prominent causes of death. In one case, the newborn died due to suffocation of the mucus which is quite different from other studies. In a study on The Maternal Mortality Rate (MMR) ${ }^{5}$ over a nine-year period (1998-2006), the MMR was $827 / 100000$ live births (471 maternal deaths against 56944 live births). An autopsy was performed in 277 cases $(58.8 \%)$. In the autopsy group, the most common causes of maternal mortality were pre-ecclampsia $(14.44 \%)$ and hemorrhage (11.55\%). However, indirect causes like infectious diseases $(9.75 \%)$ and cardiac $(9.75 \%)$ diseases also contributed to maternal deaths. ${ }^{5}$

A total of 13,074 autopsy records of fatal pulmonary 
embolism were analyzed using univariate and multivariate conditional logistic regression. Pulmonary embolism was considered fatal in 328 (2.5\%) patients. In the multivariate analysis, conditions that were more common in patients who died of pulmonary embolism were atherosclerosis, congestive heart failure and neurological surgery. Some conditions were negatively associated with fatal pulmonary embolism, including hemorrhagic stroke, aortic aneurism, cirrhosis, acquired immune deficiency syndrome and pneumonia. Interestingly, in the control group, patients with hemorrhagic stroke and aortic aneurism had short hospital stays ( 8.5 and 8.8 days, respectively) and the hemorrhage itself was the main cause of death in most of them (90.6\% and $68.4 \%$, respectively), which may have prevented the development of pulmonary embolism. Cirrhotic patients in the control group also had short hospital stays (7 days) and 50\% died from bleeding complications. ${ }^{6}$ In our study, one case died due to amniotic fluid embolism following Caesarian section, which was diagnosed after an autopsy examionation.

One neonate in our study died of suffocation with mucus due to lack of suction by the attending doctor. According to a study ${ }^{7}$, the factors associated with neonatal deaths were fetal congenital anomaly, low birth weight, first minute Apgar score under 7; zero to 3 prenatal appointments and prematurity, none of which played any role in our case which indirectly indicates that the death was due to gross medical negligence.

\section{Conclusion}

Death in hospitals as a natural event in the ordinary course of nature of the disease is unavoidable. But, deaths due to medical negligence are tragic. In this study, a significant number of the deaths could have been prevented. Public awareness of medical negligence in India is growing. Hospital managements are increasingly facing complaints regarding the facilities, standards of professional competence and the appropriateness of their therapeutic and diagnostic method. After the Consumer Protection Act, 1986 has come into force; some patients have filed legal cases against doctors, have established that the doctors were negligent in their medical service and have claimed and received compensation. To quote Mahatma Gandhi, "It is health that is a person's real wealth and not pieces of gold and silver". So as a moral obligation, everyone in the health delivery system should work together and take steps to save lives and not waste lives due to carelessness.

\section{Conflict of Interest: Nil}

\section{Acknowledgement: Nil}

\section{Source of Funding: Nil}

Ethical Clearance: Taken from Research Ethics Board,Regional Institute of Medical Sciences, Imphal.

\section{References}

1. Makary MA, Daniel M.Medical error - the third leading cause of death in the US. BMJ2016; 353 DOI: https://doi.org/10.1136/bmj.i2139(Published 03 May 2016).

2. Leape LL. Error in medicine. JAMA1994;272:18517. DOI:10.1001/jama.1994.03520230061039.

3. Hogan H, Healey F, Neale G, et al. Preventable deaths due to problems in care in English acute hospitals: A retrospective case record review study. BMJ Quality and Safety, published online July 7, 2012. https://qualitysafety.bmj.com/content/qhe/ early/2012/07/06/bmjqs-2012. Last accessed on 9 Feb 2020.

4. Hall MJ, Levant S, DeFrances CJ. NCHS Data Brief No. 118 March 2013. U.S. DEPARTMENT OF HEALTH AND HUMAN SERVICES Centers for Disease Control and Prevention National Center for Health Statistics. Trends in Inpatient Hospital Deaths: National Hospital Discharge Survey, 2000-2010.https://www.cdc.gov/nchs/products/ databriefs/db359.htm. Last accessed on 4 March 2020.

5. Panchabhai TS, Patil PD, Shah DR, Joshi AS. An autopsy study of maternal mortality: a tertiary healthcare perspective. J Postgrad Med. 2009 JanMar; 55(1):8-11.

6. Petilo SA, Bricola C, Paiva EF, Lichtenstein A, Gianini RJ, Duarte JG, Shinjo SK, Eluf-Neto J, Martins MA. Fatal pulmonary embolism in hospitalized patients: a large autopsy-based matched case-control study. Clinics (Sao Paulo). 2013 May; 68(5): 679-685.doi: 10.6061/clinics/2013(05)16.

7. De Souza S, Duim E, Nampo FK. Determinants of neonatal mortality in the largest international border of Brazil: a case-control study. BMC Public Healthvolume 19, Article number: 1304(2019). https://bmcpublichealth.biomedcentral.com/ s12889-019-7638-8. Last accessed on 5 March 2020. 